\title{
La Numeración de los indios del partido del Río Salado. Santiago del Estero, 1607. Encomiendas y servicio personal
}

The Indian Numbering in the partido of Río Salado. Santiago del Estero, 1607.

Encomiendas and personal service

\section{Isabel Castro Olañeta}

\section{OpenEdition}

Journals

Édition électronique

URL : http://journals.openedition.org/corpusarchivos/535

DOI : 10.4000/corpusarchivos.535

ISSN : 1853-8037

\section{Éditeur}

Diego Escolar

\section{Référence électronique}

Isabel Castro Olañeta, « La Numeración de los indios del partido del Río Salado. Santiago del Estero, 1607. Encomiendas y servicio personal », Corpus [En línea], Vol 3, No 2 | 2013, Publicado el 18 febrero 2014, consultado el 10 diciembre 2020. URL : http://journals.openedition.org/corpusarchivos/535 ;

DOI : https://doi.org/10.4000/corpusarchivos.535

Ce document a été généré automatiquement le 10 décembre 2020.

Licencia Creative Commons: Atribución-NoComercial 2.5 Argentina (CC BY-NC 2.5 AR) 


\section{La Numeración de los indios del partido del Río Salado. Santiago del Estero, 1607. Encomiendas y servicio personal}

The Indian Numbering in the partido of Río Salado. Santiago del Estero, 1607.

Encomiendas and personal service

Isabel Castro Olañeta

\section{NOTE DE L'ÉDITEUR}

Fecha de recepción del original: 14/07/2013

Fecha de aceptación para publicación: 11/09/2013

\section{A manera de introducción: los servicios personales en el Tucumán y las Ordenanzas de Abreu}

1 En la gobernación del Tucumán, donde el sistema colonial se consolidó paralelamente a un largo proceso de conquista ${ }^{1} \mathrm{y}$ donde el sector privado mantuvo un fuerte peso, las formas de transferencia de la fuerza de trabajo y los excedentes de las sociedades indígenas al sector privado y/o al Estado colonial a través de la imposición de un sistema de tributación anclado en el régimen de encomienda, presentó características específicas. 2

2 Siguiendo la propuesta de Gastón Doucet, la historia de la encomienda en el Tucumán en términos histórico-jurídicos admitiría una división en dos períodos marcados por la relativa legalidad del régimen de servicios personales el primero, y su tajante proscripción el segundo. La línea divisoria estaría dada por las Ordenanzas del oidor 
Francisco de Alfaro de 1612 y las características del primer período marcadas fundamentalmente por las Ordenanzas del gobernador Gonzalo de Abreu de 1576 (Doucet, 1990, pp. 141-143).

En este escrito nos centraremos en una contextualización general del primer período y específicamente de las citadas Ordenanzas, en tanto el documento que presentamos y cuyos detalles ofreceremos más adelante, es una Numeración de los indios de las encomiendas del Río Salado, cuyo registro y categorizaciones provienen, justamente, del marco legal dado por las Ordenanzas de 1576.

En la gobernación del Tucumán los indios fueron repartidos en encomiendas privadas (con las excepciones de Soconcho y Manogasta bajo cabeza real), imponiéndose un sistema opresor sobre el sistema de producción y de reproducción social, basado en la encomienda de "servicios personales". Para Doucet la encomienda de servicios personales fue el sistema de aprovechamiento directo de la mano de obra indígena donde "el tributo no es sino el resultado de la aplicación de la mano de obra que proporciona el repartimiento a empresas productivas del poseedor de éste" (Doucet, 1986, p. 95).

El sistema funcionó en la práctica como una "superposición de obligaciones", ya que los indios de encomienda no estaban tasados y no pagaban el tributo con los productos provenientes de la explotación de sus tierras comunales (Lorandi, 1988, p. 148). Se acepta que las Ordenanzas de 1576 consolidaron este sistema, en tanto solo establecían el tiempo de trabajo y no la cantidad ni la materia de los tributos (Doucet, 1986, pp. 65-66).

6 Lorandi (1988) ha planteado que la prohibición que recae constantemente sobre el servicio personal y su uso ilimitado es reiterada, pero nunca acatada, en esta región donde reinaba la discrecionalidad y la arbitrariedad de las autoridades locales y de los poderes privados que usaban y abusaban de la justicia privada; de allí que la supervivencia de este régimen sea para la autora la causa principal de un proceso marcado por la desestructuración de las sociedades prehispánicas. ${ }^{3}$

El análisis sobre las formas de tributación de las sociedades indígenas en el Tucumán colonial durante su período temprano tiene que partir de la revisión de las primeras ordenanzas dictadas por Gonzalo de Abreu en 1576, elaboradas a partir de su conocimiento del espacio de la mesopotamia santiagueña y que finalmente tuvieron como ámbito de aplicación al resto de la gobernación. ${ }^{4}$

8 Estas Ordenanzas pueden considerarse la primera intervención de un funcionario local para definir y fijar las formas y condiciones de explotación de la mano de obra indígena y el flujo de trabajo hacia el sector privado de los encomenderos. Sin embargo, a pesar de que en los Andes regían las ordenanzas toledanas que habían monetizado la tasa y reducido a los indios en pueblos, Abreu no suprimió el servicio personal como forma de tributación.

"Las Ordenanzas [de Abreu] no pretendieron hacer desaparecer el poder de los encomenderos sino, más bien, fueron sólo una primera injerencia estatal donde -el estado y los encomenderos- acordaron las normas para la explotación de los indios de paz. [...] esta Ordenanza no fijó una 'tasa' en producto o dinero ni separó al pueblo de indios del encomendero como en el resto del virreinato, al contrario, autorizó a los encomenderos para mantener a los indios como sus vasallos, es decir a mantener 'sujeta' bajo 'su jurisdicción' a toda la familia indígena sobre la cual ejercería su 'dominio' sin injerencia estatal. Desde la perspectiva institucional esta era una encomienda mixta en tanto seguían vigentes los 'servicios personales' de los indios propios de la encomienda peruana previa a $1545 \mathrm{y}$, paralelamente, se 
regulaba su duración y tipo de trabajo a través de una normativa estatal propia del período toledano" (Palomeque, 2000, pp. 114-115).

Ahora bien, si Abreu normativizó como forma permitida -aunque regulada- el servicio personal, es decir la renta en trabajo como beneficio principal de las encomiendas de la región, cabe preguntarse qué aspectos reguló y cuál era el proyecto del gobernador Abreu para el Tucumán. ${ }^{5}$ En las ordenanzas hay indicios de ello:

"queriendo remediar algunas deshordenes e malos tratamientos que algunos encomenderos les han hecho e que se aprovechasen de los dichos naturales con mas moderacion y que a ellos se les pudiese dar doctrina conbiniente yo hize e mande a pregonar cierta tasa e moderacion de la orden que de aqui en adelante se avia de tener en el aprovechamiento y servicio personal que los dichos naturales avian de dar a sus encomenderos" (En Levillier, 1920, p. 32, el resaltado me pertenece).

10 Entonces, la intervención del Estado colonial y la moderación en el aprovechamiento y servicio personal están dadas dentro del mismo sistema de entrega de tiempo de trabajo y no en el esquema de una tasación monetizada o en productos. Si bien esto ya ha sido remarcado por Lorandi y Palomeque, estimamos importante revisar algunas cuestiones nuevamente para comprender el período de transición entre estas ordenanzas y el nuevo orden normado por las ordenanzas de Alfaro de 1612, período que coincide, en sus últimos años con la gestión del gobernador Alonso de Ribera.

11 La "moderación" de Abreu intentaba operar como regulación de los tiempos y cantidades de trabajo entregadas al sector privado encomendero, e incluso al no encomendero a través de la mita. Es decir, intentaba establecer y sancionar las reglas y límites del sistema de explotación pero sin cuestionarlo.

12 Las Ordenanzas de 1576 establecen una diferenciación de los "tiempos de trabajo" de los indios encomendados, volviendo sinónimos "indios de tasa" e "indios de trabajo" en un marco en el que la territorialidad indígena aún no ha sido separada de la española y el mismo pueblo de indios de la encomienda es el espacio principal de las actividades productivas de los vecinos feudatarios.

13 En primer lugar, establece el "tiempo de mita" regulando el tiempo máximo permitido para la mita en las casas y chacras de los encomenderos (y en parte no encomenderos) en las ciudades, al cual estaban destinados el 1/10 de hombres de 15-50 años (Ord.8, en Levillier, 1920, p. 35). En segundo lugar, regula específicamente el "tiempo de los encomenderos" es decir, el tiempo de trabajo de los indios del repartimiento en las empresas productivas que tienen como base el pueblo de indios, en cual están ocupados:

- 9/10 de los hombres restantes de 15-50 años mientras no cumplían con la mita, debían trabajar en el "tiempo del encomendero" por mitades en turnos semanales:

"se puedan servir los dichos encomenderos en los dichos sus pueblos de su encomienda en sus haziendas e grangerias de la mitad de todos ellos una semana y de la otra mitad que quedaren la otra semana siguiente para que quando los unos travajaren en el beneficio y grangerias de su encomendero los de la otra mitad entiendan en sus propias haziendas de los dichos naturales" (Ord.9, en Levillier, 1920, p. 35, el resaltado me pertenece).

- las mujeres de 15-50 años debían trabajar en hilado durante 4 días a la semana: "obligadas a servir a su encomendero en los dichos pueblos de su encomienda por todo el año quatro dias en la semana desde el lunes hasta el jueves en la noche ecepto los meses de diziembre y henero porque el biernes y el savado de cada semana y los dichos dos meses an de olgar y travajar para si en sus propias haziendas" (Ord.10. Ver también Ord.11, en Levillier, 1920, p. 36, el resaltado me pertenece).

- los muchachos de 10-15 años, que no mitaban pero sí trabajaban en los pueblos: 
"al dicho su encomendero los quatro dias de la semana que an de servir las dichas yndias en hazer calcetas, coxer grana, pez y algodon y otras cossas de poco travajo y pesso todo el año continuamente y los biernes y sabados y meses de diziembre y henero travajen en lo que a sus padres e a ellos conviniere". (Ord.12, en Levillier, 1920, p. 36).

- las viejas de 50-55 y los viejos de 50-70 que no mitaban pero sí trabajaban en los pueblos: "al dicho su encomendero en guarda de algodonales chacaras de trigo maiz cevadas y otras heredades y guarda de cabras y ovejas y las viejas desde hedad de cinquenta años hasta cinquenta y cinco en hacer lossa y esteras y tener y criar aves" (Ord.13, en Levillier, 1920, p. 37).

Finalmente, estipula el tiempo de trabajo mínimo que debe dejarse libre para la reproducción de la familia indígena, una escasa diferencia y resto que queda del "tiempo de mita" y del "tiempo del encomendero" que se define como "tiempo de los indios", durante el cual se ocupan por turnos la mitad del pueblo que no está trabajando para el encomendero; los viernes y sábados de las mujeres, niños y viejos; y el "tiempo de la algarroba" que ocupa los meses de diciembre y enero, pero que en parte se entiende también como tiempo para el encomendero (Ord.16, en Levillier, 1920, pp. 37-38). ${ }^{6}$

En este marco, quedaban reservados formalmente los caciques y sus familias, los menores de 10 años, los viejos mayores de 70 y las viejas mayores de 55 mientras todo el pueblo de indios y su producción quedaba bajo el control de un agente asalariado del encomendero: el poblero. Tal como ya ha sido señalado, en el Tucumán se legalizaba una situación similar a la del Perú previa a La Gasca, por la cual "cada encomendero explotaba sus indios en una forma y con una intensidad regulada por su voluntad y capacidad para imponerla" (Palomeque, 2000, p. 113).

enenderos administraban y ponían en marcha su repartimiento como empresa productiva, gracias a la presencia directa en los pueblos de indios de un agente contratado para tal fin: el administrador, poblero, sayapaya o mayordomo, quien atendía la encomienda durante la ausencia del encomendero, lo que en realidad era la práctica habitual. Esta relación intermediada entre encomendados y encomendero, colocó a los pobleros en un lugar central en el funcionamiento de la encomienda, sobre todo por el hecho de que esta institución se complejizó y desbordó ampliamente su marco jurídico, transformándose en la base de las empresas económicas que prosperaron y enriquecieron ampliamente al sector de los vecinos feudatarios, jugando estos personajes un papel central en la explotación del trabajo indígena (Mayo, 1978).

abusos cometidos por estos agentes fueron recurrentes y contamos con numerosos documentos que referencian los malos tratos y excesos sobre los indígenas. No es casual que en 1612, las Ordenanzas del oidor Alfaro incluyan en sus primeros párrafos una frase como esta: "el demonio a introduçido en esta tierra una gente que llaman pobleros y estos son los que inmediatamente hacen los agravios" (Levillier 1918, p. 288), justificando luego la prohibición de su nombramiento y presencia en los pueblos de indios que había sido permitida por Abreu casi sin control, mientras prohibía la presencia del encomendero, su esposa y familia.

18 Sin embargo, no fue Francisco de Alfaro el único alertado por los abusos de los pobleros. Antes que él, principios del siglo XVII, el gobernador Ribera, preocupado por los abusos y la consecuente disminución de los indios naturales, no solamente escribió al rey denunciando los excesos de los españoles, sino que intentó hacer cumplir las ordenanzas de 1576 al mismo tiempo que manifestaba en reiteradas oportunidades su intención de tasar los tributos. De acuerdo con la documentación revisada hasta el momento y la 
reciente investigación de Carmignani (2013), podemos asegurar que la política de Ribera es el antecedente local más cercano al proyecto que llevó adelante el oidor de Charcas con su Visita y Ordenanzas.

\section{El gobernador Alonso de Ribera, la aplicación de las Ordenanzas de Abreu y la visita de los tenientes de naturales}

Solo dos años después de dictadas las Ordenanzas del gobernador Abreu, en 1578,

"el virrey Toledo, a quien nadie calificaría como pro-indígena, desconoció la legalidad de esta Ordenanza y le ordenó al nuevo gobernador que regularizara la situación en el Tucumán donde 'no han sido tasados ni moderados los tributos' que quitara los servicios personales, redujera los indios a sus pueblos, tasara los tributos en los productos propios de la zona y que sólo se considerara tributarios a los hombres de 18 a 50 años" (Palomeque, 2000, p. 115).

Palomeque señala que estas instrucciones que buscaban limitar la discrecionalidad que permitían las ordenanzas, no fueron acatadas.

Como ya adelantamos, desde fines del siglo XVI circulaban en la Gobernación e incluso en la Audiencia de Charcas una serie de denuncias sobre los abusos, excesos y malos tratos que sufrían los indios del Tucumán. ${ }^{7}$ Con la gestión de Alonso de Ribera (1605-1611)8 estas denuncias se articulan en torno al proyecto político del gobernador quien se hizo eco de las mismas y trató de remediar la situación utilizando el marco normativo vigente -las ordenanzas de Abreu-como instrumento para bajar los altos niveles de explotación, al mismo tiempo que intentaba dar un paso más solicitando que se "tasara la tierra", es decir, que se anularan los servicios personales.

Alonso de Ribera le dirá al monarca en marzo de 1607 que

"las dichas ordenanzas del governador Gonçalo [...] no ay quien las guarde en este tierra ay muchos excessos sobre su cumplimiento que como digo voy remediando [...] ire reformando dellas las que tubiere necessidad de reformacion y are otras muy necesarias para la conservacion y bien de los naturales y españoles". (en Carmignani, 2013, p.139)

En este mismo sentido, el gobernador también expresaba reiteradamente su intención de tasar:

"desde que llegue a este govierno e mirado y considerado con mucho cuidado y diliigencia la traça y orden que podria dar para el alibio y descanso de los naturales y descargo de vuestra real conciencia para tassarlos como los de las demas provincias del Piru y para ponerlo en execusion" (AGI.Charcas,26,R.8,N.39).

Si bien el objetivo al mediano plazo de Alonso de Ribera era visitar y tasar a los indígenas encomendados en particulares y reformar o incluso hacer nuevas ordenanzas para la gobernación, ya que pensaba que las de Gonzalo de Abreu eran injustas y no se adecuaban a la política implantada por Toledo en Andes centrales, su accionar al corto plazo se orientó a amparar a los indios en su justicia dentro de la misma legalidad de las ordenanzas que quería reformar. Ribera sabía que aunque las Ordenanzas de 1576 eran sumamente favorables para el sector privado, aún así, eran desacatadas, y se registraba un conjunto de abusos y excesos que podían controlarse desde el Estado colonial si este se constituía como guardián de las mismas (Carmignani, 2013). 
Pero además, más allá de su declamación sobre la necesidad de una visita de la tierra, podemos afirmar que Alonso de Ribera tomó medidas concretas durante su gestión de gobierno y que la más contundente se orientó contra los pobleros que, tal como hemos señalado, operaban como uno de los aspectos más terribles del sistema de explotación de la mano de obra indígena permitido por las Ordenanzas de 1576.

Lo más interesante es que el gobernador, para accionar contra estos agentes del encomendero, tomó como modelo la reforma toledana aplicada en el Perú. Su intervención práctica radicó en introducir funcionarios que mediaran en la relación entre los indios y sus encomenderos pero controlados desde el Estado colonial, y se materializó con el nombramiento de "tenientes de naturales", a semejanza de los corregidores andinos para que actuaran como garantes $-\mathrm{y}$ brazo ejecutor del gobernador- de las ordenanzas de 1576 para amparar a los indios en su justicia. Dice Ribera:

"me funde en que las hordenanzas de don Françisco de Toledo que por orden de Vuestra Magestad estan mandadas guardar en todas las provinçias del Piru diçen que aya corregidores en los pueblos de natturales y como esta es una dellas puse los dichos tenientes para que los anparasen y mantubiesen en justicia" (En Carmignani, 2013, p. 106, el resaltado me pertenece).

Además, los tenientes de naturales permitirían no solo frenar los abusos de los encomenderos y pobleros, sino también evitar las juntas y borracheras de los indios en el "tiempo de la algarroba", es decir serían parte de una burocracia estatal que tendría injerencia sobre la territorialidad de los pueblos de indios con jurisdicción sobre españoles e indígenas, muy similar a la de los corregidores (Carmignani, 2013, pp. 89-112).

En una carta de mayo de 1607, Ribera informaba que

"para el descargo de la real conciençia de Vuestra Magestad y bien y aumento desta provincia y en esta conformidad me fui ynformando de las ordenanças que avia puestas y el orden que avia en su oservancia y alle que no tenian otros executores sino los mismos encomenderos contra quien se avian hecho a cuya causa no avia cunplimiento en ninguna dellas antes exçedian en todas con gran daño destos natturales, por lo qual y por ser esta provincia tan dilatada que no es posible que el que la govierna pueda alcanzar a açer justiçia en toda ella perssonalmente ni con los ministros que tiene, provei tenientes de natturales para que hiziesen cunplir las ordenanças" (AGI. Charcas,26,R.8,N.41, el resaltado me pertenece).

Alonso de Ribera nombró tenientes de naturales para toda la gobernación: en Santiago del Estero visitaron los tres partidos del Río Salado, del Río Dulce, y de la Sierra y valle de Catamarca; en La Rioja los partidos del valle de Famatina y de Londres; en Córdoba el Partido de los Ríos, el de Quilino y el de Soto; y finalmente, el partido único de la ciudad de San Miguel de Tucumán. También se nombraron un teniente para Esteco y otro para Salta, Jujuy y Las Juntas, pero estos no llegaron a realizar sus visitas debido a la medida de suspensión que llegó desde Charcas en respuesta a las quejas de los cabildos por las medidas tomadas por el gobernador (Carmignani, 2013, pp. 89-125).

o Sin embargo, más allá de lo breve de la acción, los tenientes elaboraron informes como resultado de sus visitas que fueron elevados al gobernador; en ellos se detallan los castigos que dieron a los pobleros que habían cometido delitos, cómo iban reservando del trabajo a los exentos por las ordenanzas y hacían saber a los indios que los que los maltrataban serían castigados por los representantes locales de la Corona. ${ }^{9}$

Entendemos que la gestión de Alonso de Ribera constituye el inicio de una coyuntura política favorable a las sociedades indígenas que tuvo como consumación la Visita y Ordenanzas del oidor Francisco de Alfaro. El gobernador actuó como un funcionario 
preocupado por la conservación de los naturales y llevó adelante un proyecto político de intervención con el claro objetivo de castigar los abusos de pobleros y encomenderos contra los indios y modificar las ordenanzas vigentes de 1576, tomando como modelo la reforma toledana aplicada en las regiones centrales del virreinato y cuya medida más significativa fue la designación de tenientes y sus visitas.

\section{El documento: La Numeraçion de los indios del Río Salado}

32 Un documento que se complementa con los Informes de los Tenientes y que brinda información acerca de las magnitudes de los repartimientos e indirectamente sobre la reserva de mano de obra indígena con la que contaba el sector privado bajo el sistema de los servicios personales, es el padrón o más precisamente la "Numeraçion" realizada por el teniente del partido del Río Salado en el marco de su visita, el cual fue elevado junto con su Informe al gobernador Alonso Ribera.

Como ya hemos planteado, de la ciudad de Santiago del Estero dependían tres partidos: el del Río Salado, el del Río Dulce y el de la Sierra y, precisamente, el padrón que aquí se presenta fue resultado de la labor del Teniente de Naturales Francisco Luis en el partido del Río Salado en el año de 1607.

El original de este documento se encuentra en el Archivo General de Indias (AGI), Sevilla, dentro de la serie "Cartas de Gobernadores" bajo la signatura Charcas, 26, R.8, N.41 y con el texto que, a manera de título, dice:

"Numeraçion de todos los caciques e yndios e yndias tributarios y biejos y biejas reservadas del travaxo que ay en todo el distrito del Rio Salado sacados del padron general que hizo el capitan Francisco Luis teniente de gobernador y justicia mayor en el dicho distrito, son los siguientes".

El acceso al documento se realizó a través del Portal de Archivos Españoles ${ }^{10}$ y se realizó la transcripción paleográfica del documento siguiendo los criterios establecidos por las Normas para la Transcripción de Documentos Históricos Panamericanos aprobadas en Washington en 1961 (en Tanodi, 2000).

La Numeraçion consta de dos folios y se ubica en el Bloque 3 de las imágenes digitales brindadas por el portal mencionado. Este documento fue incluido como un anexo de una de las cartas elevadas al monarca por el gobernador Alonso de Ribera el 16 de mayo de 1607 que refiere a las actuaciones de los tenientes de naturales.

37 La inclusión de la Numeraçion en la carta al monarca tenía el objetivo de señalar la manera y la "horden que se llevava para que los indios empadronasen toda la provincia y que Vuestra Magestad y si Real Consejo supiesse lo que tiene en ella" y denunciar que debido a la protesta de los encomenderos que tuvo eco en la Audiencia de Charcas, "todo cesso [...] y no se volvera a acer nada sin nueva horden de Vuestra Magestad" y debido a esto "y por el poco tiempo que estuvieron en sus oficios no se pudo pasar el limpio mas que este partido ques uno de los tres desta ciudad" (AGI. Charcas,26,R.8,N.41, Bloque 3, f.1v). ${ }^{11}$

38 Si bien se encuentran dos transcripciones paleográficas de la Numeraçion realizadas a principios de siglo XX - una perteneciente a la Colección Gaspar García Viñas en Buenos Aires y la otra al Fondo Documental Mons. Pablo Cabrera en Córdoba- ${ }^{12}$, y se trata de un documento consultado por otros investigadores (González Rodríguez, 1984; Doucet, 1987; 
Farberman, 2011), el mismo hasta el momento se encontraba inédito de manera completa y precisa, a pesar de su gran importancia para los estudios etnohistóricos y de historia colonial de la región. González Rodríguez ha publicado un cuadro con los datos del documento en cuestión (González Rodríguez, 1984, p. 21); sin embargo, el mismo contiene errores en algunos números expresados y el documento no se transcribe en su totalidad; además de no contar con una contextualización que permita valorar la excepcionalidad del mismo.

La Numeraçion se estructura por repartimientos o encomiendas y, a manera de un cuadro de doble entrada, brinda bajo el nombre de su titular o encomendero la cantidad de caciques, de indios de trabajo, de indias de hilado, de viejos y viejas reservadas, de muchachos y muchachas. Tomando las Ordenanzas de Abreu como marco normativo y clasificador de la población, se consideran "indios de trabajo" (entendido como sinónimo de tributarios) a los hombres de 15 a 50 años, y "mujeres de hilado", a las mujeres del mismo rango etario. Incluye también a viejos y viejas reservados, y a muchachos y muchachas pre-tributarios. Esta Numeraçión permite visualizar la afectación de toda la unidad doméstica en las distintas actividades productivas que beneficiaban al encomendero.

En cifras, se registra para 1607 en el partido del Río Salado (sólo uno de los tres partidos de dicha jurisdicción) un total de 4791 indígenas distribuidos en 19 encomiendas (casi la mitad del total de las 42 encomiendas existentes en Santiago en ese momento) ${ }^{13}$ según las siguientes categorías:

\section{Cuadro $\mathrm{N}^{\circ} 1$}

\begin{tabular}{|l|l|l|l|l|l|l|l|}
\hline $\begin{array}{l}\text { Yndios de } \\
\text { travaxo }\end{array}$ & $\begin{array}{l}\text { Indias de } \\
\text { ylado }\end{array}$ & $\begin{array}{l}\text { Biejos } \\
\text { reservados }\end{array}$ & $\begin{array}{l}\text { Biejas } \\
\text { reservadas }\end{array}$ & Muchachos & Muchachas & caciques & Total \\
\hline 1359 & 1310 & 283 & 410 & 870 & 426 & 133 & 4791 \\
\hline
\end{tabular}

41 Como podemos observar del cuadro de síntesis, para el partido del Salado en 1607 se registran 4791 naturales -incluyendo 133 caciques- de los cuales 1359 son indios tributarios o "de trabajo" (según las ordenanzas de Abreu, hombres entre 15 y 50 años) y 1310 indias hilanderas (de 12 a 50 años).

Un apartado sobre la cantidad de reservados, los 283 viejos y 410 viejas. Por las cartas de Ribera sabemos que una de las comisiones principales de los tenientes era reservar a los viejos y a los niños del trabajo impuesto por encomenderos y pobleros, lo que implica que antes de la visita, los viejos y niños no estaban necesariamente "reservados" en los términos de las ordenanzas de Abreu (Carmignani, 2013, pp. 154-155).

Como señalamos, el documento consigna los nombres de los encomenderos del Río Salado, pero no se brindan los topónimos o etnónimos que nos permitan reconstruir a qué pueblos corresponde cada encomienda, por lo que la identificación de los asientos solo es posible contrastando la Numeraçion con otro tipo de fuentes documentales.

Para lograr una primera reconstrucción, contrastamos la Numeraçion con la "Descripción general de Santiago del Estero" de octubre de 1608, conocido también como Censo o Memorial de 1608 (en Pérez Saez y Osán, 1997, pp. 17-108), documento de excepcional riqueza que registra las respuestas de los vecinos de la ciudad a un Memorial de 
preguntas muy variadas, entre las cuales está precisamente el nombre de la encomienda que poseían los vecinos. ${ }^{14}$ Con una estrategia metodológica de contrastación básica, logramos reconstruir el siguiente cuadro que permite contar con los datos básicos de las encomiendas del Río Salado, el asiento, pueblo o conjunto de pueblos encomendados y el nombre de su titular para 1607-1608.

\section{Cuadro $\mathrm{N}^{\circ} 2$}

\begin{tabular}{|c|c|}
\hline Numeracion 1607 & Memorial 1608 \\
\hline $\begin{array}{l}\text { Repartimiento de don Pedro de } \\
\text { Barrasa y Cardenas (sic) }\end{array}$ & Pedro de Barrasa y Frias: San Joan de Lasco \\
\hline $\begin{array}{l}\text { El repartimiento del capitan Garcia } \\
\text { Barata }\end{array}$ & Lonsaya y Sichagasta \\
\hline $\begin{array}{l}\text { El repartimiento del capitan } \\
\text { Gonzalo Gonzales }\end{array}$ & Gonzalo Gonzalez Cruçado: Mancapa \\
\hline $\begin{array}{l}\text { El repartimiento de Garçia de } \\
\text { Herrera }\end{array}$ & Telingo y Libapa \\
\hline $\begin{array}{l}\text { El repartimiento de Juan Dias } \\
\text { Cavallero }\end{array}$ & Calabalax \\
\hline $\begin{array}{l}\text { El repartimiento del alferez Martin } \\
\text { de Ledesma }\end{array}$ & $\begin{array}{l}\text { Martín de Ledesma Valderrama: Indios originarios del } \\
\text { Río Salado, trasladados a la ciudad para el servicio de } \\
\text { casa y chacra }\end{array}$ \\
\hline $\begin{array}{l}\text { El repartimiento de doña Maria de } \\
\text { Godoy }\end{array}$ & $?$ \\
\hline El repartimiento de Garcia Dabiles & "son chiriguanaes los mas" \\
\hline $\begin{array}{l}\text { El repartimieto del capitan Gaspar } \\
\text { Rodriguez }\end{array}$ & Chapisgasta \\
\hline $\begin{array}{l}\text { El repartimiento del maestre de } \\
\text { campo Alonso de Herrera y Guzman }\end{array}$ & Tatingasta? \\
\hline $\begin{array}{l}\text { El repartimiento de Cosme del } \\
\text { Campo }\end{array}$ & Caniqui y Calchanga \\
\hline $\begin{array}{l}\text { El repartimiento del capitan Miguel } \\
\text { Albares de Abila }\end{array}$ & Chequina y Guanogasta \\
\hline $\begin{array}{l}\text { El repartimiento del general Sancho } \\
\text { de Paz }\end{array}$ & Guaype \\
\hline $\begin{array}{l}\text { El repartimiento de Garsi Sanchez } \\
\text { de Garnica }\end{array}$ & Mopa \\
\hline
\end{tabular}




\begin{tabular}{|l|l|}
\hline El repartimiento de Diego de Çepeda & Asogasta \\
\hline $\begin{array}{l}\text { El repartimiento de Hernando de } \\
\text { Quintana }\end{array}$ & Meaxa \\
\hline $\begin{array}{l}\text { El repartimiento de Joana Nuño } \\
\text { Roldan (viuda de Sotelo de Narvaez) }\end{array}$ & Yuquiliguala \\
\hline $\begin{array}{l}\text { El repartimiento del menor Juan } \\
\text { Xuarez Babiano }\end{array}$ & Ystail? \\
\hline $\begin{array}{l}\text { El repartimiento de la biuda Leonor } \\
\text { de Carneros }\end{array}$ & Leonor de Cameros: Alagastina y Mosgasta \\
\hline
\end{tabular}

Volviendo a las cifras brindadas por el padrón, varios de los datos ofrecen interrogantes que creemos importante poner en discusión, pero que exigen un trabajo más detenido y profundo del que se ensaya aquí.

En primer lugar, el elevado número de caciques, que en las encomiendas más cuantiosas llegan a una docena e incluso a 23. ¿Cuál era la organización política y jerarquía de autoridades que persistía luego de medio siglo de dominación española en tierras bajas? ¿Hasta dónde se mantenían grupos que respondían a autoridades étnicas diferentes, articulados socialmente entre sí? ¿Existían relaciones jerárquicas entre ellos o el repartimiento unía bajo la misma titularidad unidades políticas pequeñas pero independientes? La relación entre cantidad de caciques y población sujeta y el alto número de caciques, ¿es indicador de la forma local de organización política o resultado de la caída demográfica?

Quisiéramos recuperar la idea de que las sociedades de la mesopotamia estaban asentadas en muchas aldeas, cercanas unas de otras y sin centros urbanos y políticos dominantes sobre el conjunto. ${ }^{15}$ Tal como describía Diego Fernandez (1571), las huestes de Diego de Rojas "descubrieron una gran provincia de tierra muy poblada y a media legua los pueblos unos de otros de a ochocientas a mil casas..." (en Berberian, 1987, p. 52).

En el mismo sentido, Sotelo de Narváez (1582) nos brinda dos datos de importancia. En primer lugar, la existencia de muchos pueblos a lo largo del río Salado de los cuales sólo se nombran Yocoliguala (donde comienzan los indios que sirven a Santiago) y Colosaca y Calabalax (donde terminan):

"El Río Salado [...] pasa doce leguas destroto [río Dulce]; están en él poblados indios que sirven a la ciudad de Santiago y entran en el número dicho; [...] comienzan los pueblos que sirven a Santiago dende un pueblo que se llama Yocoliguala hasta otro que se dice Colosaca y Calabalax. Hay muchos en medio destos, y de ahí abajo están de guerra. Los más destos pueblos hablan lengua que dicen tonocote..." (en Jaimes Freyre, 1915, p. 89) (el resaltado me pertenece).

Para principios del siglo XVII, en el mismo momento de la Numeraçión, el gobernador Ribera decía que el "pueblo de indios que mas llega a tener es ducientos" (refiriéndose al pueblo de Tatingasta, como el más grande en el partido del Salado y en toda la jurisdicción de Santiago); "todos los demas son de menos numero de indios los quales pueblos estan de distancia unos de otros a tres y a cinco leguas y corren hasta cinquenta" (en Larrouy, 1915, p. 159). 
50 Podría hipotetizarse que los repartimientos del Río Salado conservaron, en gran medida, su distribución y tipo de asentamiento, a diferencia de los del Río Dulce que fueron más afectados por el asentamiento y dominio español. Siguiendo a Palomeque,

"todo este proceso [de larga conquista] terminaría por debilitar el denso asentamiento indígena en la zona del río Dulce, con lo cual el Salado pasaría a ser el área de mayor preservación, tal como se expresa en el Informe de 1608 cuando se señala que la mayor población indígena se asienta sobre el Salado, cuando las referencias más tempranas indicaban una mayor concentración poblacional estaba en las costas del río Dulce" (Palomeque, 2009, p. 199).

51 Lamentablemente, aún no hemos ubicado cédulas de encomienda tempranas que nos permitan ensayar con más elementos las hipótesis acerca de la conformación sociopolítica y las relaciones entre los conjuntos poblacionales menores o aldeas, y las unidades mayores en los cuales se integraban en esta zona, que parecen responder a un patrón de asentamiento marcado por la dispersión de las aldeas de alta densidad poblacional.

Entendemos que debemos pensar la conformación prehispánica y organización política de la sociedad indígena que se asentaba en los ríos, como un conjunto de estructuras que fueron transformadas $-\mathrm{y}$ no necesariamente destruidas - en el proceso iniciado con la conquista y colonización. A partir de este supuesto, podríamos hipotetizar que cada repartimiento entregado a un español incluía uno, dos, tres o más pueblos o parcialidades indígenas que habían sido relativamente autónomos en tiempos prehispánicos, e incluso cada uno contaba con su propio cacique.

Analizando algunas líneas de documentos tempranos, podemos ayudar a reconstruir esta imagen: un vecino de la ciudad a fines de la década de 1580 decía que:

"los vecinos de santa fe del rio de la plata habian corrido los terminos de esta ciudad y se habian llevado seis o siete pueblos de indios repartidos en esta ciudad a Juan Diaz Caballero que a mas de treinta y cinco años que los tiene en encomienda y servidumbre [...] y que a este testigo se lo han dicho como a hombre que tiene a su cargo muchos pueblos en el Rio Salado de un menor suyo" (En Levillier, 1918, pp. 250-251) (el resaltado me pertenece).

54 Si trasladamos la hipótesis al cuadro anterior, y tomando como ejemplo el caso de la encomienda de Calabalax, podemos señalar que los 13 caciques que pertenecían a la encomienda de Juan Díaz Caballero eran, como mínimo, las autoridades de seis o siete pueblos de indios. Si consideramos a Lasco, podemos suponer que los 14 caciques que pertenecen al repartimiento de Pedro de Barrasa, eran las autoridades de varios pueblos o parcialidades entregadas a un mismo español y que tomaron la denominación del más importante de ellos.

Si nuestra hipótesis es acertada, resultaría que a 50 años de asentados los españoles en el territorio, aún el sistema de autoridades tradicional conservaba algunas de sus características o, por lo menos, no se habría operado un proceso de fusión como resultado del sistema de encomiendas, y por lo tanto debemos dejar abierta la posibilidad de que debajo del rótulo "pueblo de San Joan de Lasco", "Lasco" o "repartimiento de don Pedro de Barrasa", siguiera funcionando una organización y asentamiento aldeano con autoridades étnicas diferenciadas.

Por otra parte, también podríamos considerar la posibilidad de que el mantenimiento de las autoridades étnicas se haya anclado en la necesidad del sistema colonial para conseguir y canalizar el trabajo de la mano de obra de sus indios sujetos, bajo el régimen 
de servicios personales, y aplicado a múltiples actividades productivas, especialmente el hilado y el tejido.

Retomando las reflexiones iniciales acerca del servicio personal, y agregando a ellas los planteos de C.S. Assadourian, podemos recordar que si bien los encomenderos del Tucumán tenían rasgos señoriales, estos no pueden ser caracterizados como una aristocracia ociosa. Más correcto es definirlos como "agricultores-comerciantes", minoría dirigente y empresarios, en el marco de una economía de cambio (Assadourian, 1972, pp. 93-94). Esta participación económica activa de los conquistadores devenidos en encomenderos dio como primer resultado -en el período más temprano posterior a la invasión, fundación de ciudades y toma de encomiendas- la creación de una economía de autosubsistencia mediante el uso de la fuerza laboral indígena y la introducción de plantas y animales europeos; pero, a corto plazo, las ciudades contaron con abundancia de productos de la tierra prestos a ser mercantilizados (Assadourian, 1972, p. 97).

Esta producción excedente de efectos de la tierra, muy tempranamente comercializados en los circuitos activados por el centro minero potosino, se basó en la expropiación de las tierras indígenas y en la explotación del trabajo de los indios sometidos bajo el régimen de servicios personales. Es en este marco que debemos analizar las producciones locales del distrito de Santiago del Estero, con la información provista en parte por la Numeraçión (que nos muestra que, a pesar de la fuerte caída demográfica, las encomiendas del Salado seguían siendo de las más grandes de la gobernación a principios del siglo XVII), pero también con los Informes de los tenientes, resultados de sus visitas a los tres partidos.

Los Informes no hacen más que confirmar no sólo las características del funcionamiento de la encomienda de servicios personales, sino también los excesos y abusos sobre los límites establecidos por las Ordenanzas de 1576: trabajo de reservados, de caciques y sus familias, muchachos y niños; trabajo continuo y sin descanso ni días de fiesta. Así, los indios solo trabajan en la producción del encomendero.

Sabemos también por los Informes de los tenientes para Santiago del Estero, que los más de 1300 indios de trabajo del Río Salado se ocupaban de variadas actividades en la hacienda de su encomendero: cultivos y producción de comidas, guarda de ganado, fletes para viajes de media y larga distancia, vaquerías, construcción y obras de casas, recolección de grana, confección de alpargatas, hilado y tejido de lana. Sin embargo, la principal actividad en la cual estaban ocupados era el cultivo de algodón, su hilado y tejido. ${ }^{16}$ Se puede deducir que las indias se ocupaban del hilado y los hombres del tejido, al mismo tiempo que podemos intuir que las sociedades indígenas conservaban a duras penas un ganado de comunidad (ovejas, vacas, caballos, gallinas y puercos) ya que los encomenderos lo expropiaban y lo vendían para sí, al mismo tiempo que era la lana de este ganado la que se daba de "guarco":

"del ganado de sus comunidades del qual ay en el Rio Salado diez y siete mill cauezas y los yndios no tienen del ningun prouecho porque los vezinos les esquilman el multiplico y las lanas sin dar prouecho a los yndios" (en Carmignani, 2013, pp. 180-189).

61 Resumiendo, el documento que presentamos aquí es un ejemplo de la organización y del registro de la población indígena encomendada y que se encontraba bajo el régimen de servicio personal en la gobernación del Tucumán en la coyuntura prealfariana, particularmente en el marco de la gestión del gobernador Alonso de Ribera y de la vigencia de las Ordenanzas del gobernador Abreu. 


\section{BIBLIOGRAPHIE}

Assadourian, C. (1972). La conquista. En C. Assadourian, G. Beato y J. Chiaramonte, Historia Argentina. De la conquista a la independencia (pp. 13-114). Buenos Aires: Paidos.

Berberian, E. (1987). Crónicas del Tucuman, siglo XVI. Comechingonia. Córdoba.

Carmignani, L. (2013). Política colonial y sociedades indígenas en la Gobernación del Tucumán. El gobernador Alonso de Ribera, los Tenientes de Naturales y la elite encomendera durante la vigencia de las Ordenanzas de Abreu. Tesis de Licenciatura en Historia, inédita, UNC, FFyH, Escuela de Historia, Córdoba.

Castro Olañeta, I. (2006). Transformaciones y continuidades de sociedades indígenas en el sistema colonial. El pueblo de indios de Quilino a principios del siglo XVII. Córdoba: Alción Editora.

Castro Olañeta, I. (2010a). Indios de trabajo e indias de hilado: un acercamiento etnohistórico a las encomiendas del Río Salado (Santiago del Estero, fines s. XVI-principios s. XVII). En $X^{\circ}$ Encuentro de Jóvenes Investigadores de Santiago del Estero. EJI/10, 5 al 9 de octubre.

Castro Olañeta, I. (2010b). Servicio personal, tributo y conciertos en Córdoba a principios del siglo XVII. La visita del gobernador Luis de Quiñones Osorio y la aplicación de las Ordenanzas de Francisco de Alfaro. Memoria Americana. Revista de la Sección Etnohistoria del Instituto de Ciencias Antropológicas. Facultad de Filosofía de la Universidad de Buenos Aires. XVIII (2), 101-127.

Castro Olañeta, I. y Carmignani, L. (2009). La visita de los tenientes de naturales del gobernador Alonso de Ribera al Tucumán y la numeración de los indios tributarios del Río Salado en Santiago del Estero de 1607. Avances de Investigación y transcripción paleográfica de documentos inéditos. En IXํㅡㄹ Encuentro de Jóvenes Investigadores de Santiago del Estero. EJI /9, 13 al 17 de octubre.

Crouzeilles, C. (2007). Religiosos y sociedad colonial. Los religiosos, su ingreso al Tucumán y su incidencia política en el sistema de explotación económico sobre la sociedad indígena (Tucumán, 1535-1615). Trabajo Final Licenciatura en Historia inédito, UNC, FFyH, Escuela de Historia, Córdoba.

Doucet, G. (1986). Los réditos de Quilpo: funcionamiento de una encomienda cordobesa a fines del siglo XVI. Jahrbuch für Geschichte von Staat Wirtschaft und Gesellschaft Lateinamerikas, 23. Colonia, 63-119.

Corpus, Vol 3, No 2 | 2013 
Doucet, G. (1987). En torno a la población aborigen y a las encomiendas de Indios del antiguo Tucumán. Acotaciones a un libro laureado. Revista de Indias, XLVII (179), 253-313.

Doucet, G. (1990). La encomienda de servicio personal en el Tucumán, bajo régimen legal: comentarios a las Ordenanzas de Gonzalo de Abreu. En A. Levaggi (Coord.), El aborigen y el derecho en el pasado y el presente (pp. 141-244). Buenos Aires: Universidad del Museo Social Argentino.

Doucet, G. (1998). Vecinos, moradores, residentes y otros habitantes de tres ciudades tucumanenses en 1608. Genealogía. Revista del Instituto Argentino de Ciencias Genealógicas, 29, 497-542.

Farberman, J. (2011). Entre intermediarios fronterizos y guardianes del Chaco: la larga historia de los mataraes santiagueños (siglos XVI a XIX). Nuevo Mundo Mundos Nuevos [En línea], Debates, Disponible en: http://nuevomundo.revues.org/61448

Farberman, J. y Gil Montero, R. (2002). Los pueblos de indios del Tucumán colonial: pervivencia y desestructuración. Bernal: EdiUnju/Universidad Nacional de Quilmes.

Farberman, J. y Taboada, C. (2012). Las sociedades indígenas del territorio santiagueño: apuntes iniciales desde la arqueología y la historia. Período prehispánico tardío y colonial temprano. Runa , XXXIII. 2, FFyL-UBA, 113-132.

González Rodríguez, A. (1984). La encomienda en Tucumán. Sevilla: Publicaciones de la Excma. Diputación Provincial de Sevilla.

Jaimes Freyre, R. (1915). El Tucumán colonial. Documentos y mapas del Archivo de Indias, I. Buenos Aires: Imprenta y Casa Editoria de Coni Hermanos.

Larrouy, A. (1915). Documentos relativos a Nuestra Señora del Valle y a Catamarca. Santuario de Nuestra Señora del Valle. Tomo I. 1591-1764. Buenos Aires: Cia. Sudamericana de Billetes de Banco.

Levillier, R. (1918). Gobernación del Tucumán. Correspondencia de los cabildos en el siglo XVI. Documentos del Archivo de Indias. Madrid: Sucesores de Rivadeneyra.

Levillier, R. (1920). Gobernación del Tucumán: Papeles de gobernadores en el siglo XVI. Documentos del Archivo de Indias. Madrid: Biblioteca del Congreso Argentino.

Lorandi, A. (1988). El servicio personal como agente de desestructuración del Tucumán colonial. Revista Andina, VI (1), Cusco, 135-173.

Lorandi, A. (1997). Introducción. En A. M. Lorandi (Comp.), El Tucumán Colonial y Charcas. I (pp. 15-71). Buenos Aires: FFyL-UBA.

Lorandi, A. (2002). Introducción. En J. Farberman y R. Gil Montero (Comps.). Los pueblos de indios del Tucumán colonial: pervivencia y desestructuración, (pp. 9-14). Buenos Aires: EdiUnju y Universidad Nacional de Quilmes.

Luque Colombres, C.A. (Dir.). (1974). Actas Capitulares. Libro Primero: Ordenanzas acerca de los naturales de la ciudad de Córdoba. Córdoba, 23-V-1579 (pp. 298-301). Archivo Municipal de Córdoba.

Mayo, C. (1978). Los pobleros del Tucumán colonial: contribución al estudio de los mayordomos y administradores de encomienda en América. Revista de Historia de América, 85. México: Instituto Panamericano de Geografía e Historia, Comisión de Historia, 27-57.

Noli, E. (1999). La recolección en la economía de subsistencia de las poblaciones indígenas: una aproximación a través de fuentes coloniales (piedemonte y llanura tucumano-santiagueña, Gobernación del Tucumán). En C. Aschero, M. Korstanje y P. Vuoto (Eds.), En los tres reinos: prácticas de recolección en el cono sur de América, (pp. 205-215). Tucumán: Instituto de Arqueología y Museo, UNT. 
Palomeque, S. (2000). El mundo indígena. Siglos XVI-XVIII. En E. Tandeter (Dir.), Nueva Historia Argentina II: La sociedad colonial, (pp. 87-143). Buenos Aires: Sudamericana.

Palomeque, S. (2009). El Tucumán durante los siglos XVI y XVII. La destrucción de las 'tierras bajas' en aras de la conquista de las 'tierras altas'. En Y. Martini, G. Pérez Zavala y Y. Aguilar (Comps.), Las sociedades de los paisajes semiáridos y áridos del centro-oeste argentino. VII Jornadas de Investigadores en Arqueología y Etnohistoria del centro-oeste del país, (pp. 173-206). Río Cuarto, Córdoba: UNRC.

Perez Saez, V. y Osan de Perez Saez, M. (1997). El español de la Argentina. Documentos para su historia (Noroeste), I. Salta: UNSa.

Quiroga, L. (1999). Los dueños de los montes, aguadas y algarrobales. Contradicciones y conflictos coloniales en torno a los recursos silvestres. Un planteo del problema. En C. Aschero, M.

Korstanje y P. Vuoto (Eds.), En los tres reinos: prácticas de recolección en el cono sur de América, (pp. 217-226). Tucumán: Instituto de Arqueología y Museo, UNT.

Taboada, C. (2011). Repensando la arqueología de Santiago del Estero. Construcción y análisis de una problemática. Relaciones de la Sociedad Argentina de Antropología, XXXVI, Buenos Aires, 197-218..

Taboada, C. y Angiorama, C. (2008). Metales andinos en la llanura santiagueña (Argentina). Revista Andina, 47, 117-150. Cuzco: Centro Bartolomé de las Casas.

Taboada, C. y Angiorama, C. (2010). Metales, textilería y cerámica: tres líneas de análisis para pensar una vinculación entre los habitantes de la llanura santiagueña y el Tawantinsuyu. Memoria Americana, XVIII, I Buenos Aires: Sección Etnohistoria, FFyL-UBA, 11-41.

Tanodi, B. (2000). Documentos históricos. Normas de Transcripción y Publicación. Cuadernos de Historia. Serie Economía y Sociedad (3) Córdoba: CIFFyH-UNC, 259-270.

\section{NOTES}

1. Sobre el largo proceso de conquista y el conflictivo avance sobre las tierras altas de los españoles asentados en las frágiles ciudades de las tierras bajas del Tucumán, ver Palomeque 2000 y 2009.

2. Este problema general no es novedoso, ya que ha sido desarrollado tempranamente por Ana María Lorandi (1988; 1997), Gastón Doucet $(1986 ; 1987 ; 1990)$ y luego por Silvia Palomeque (2000; 2009) quien recuperó los aportes de ambos autores y los posteriores avances sobre el tema proponiendo nuevas líneas de análisis e hipótesis de trabajo.

3. Este planteo se ubicó como el eje central que marcó las posteriores investigaciones acerca del impacto de la conquista y colonización de las sociedades indígenas en el Tucumán, y si bien ha sido matizado por la autora (Lorandi, 1997; 2002), no ha sido cuestionado en sus líneas generales. Dos líneas principales han sido revisadas en los últimos 30 años: la supervivencia de los pueblos de indios más allá del contexto de desestructuración (Palomeque, 2000 y Farberman y Gil Montero, 2002) y las formas diferenciadas y manipuladas en las que continúa el servicio personal luego de las Ordenanzas de Alfaro (Castro Olañeta, 2010b).

4. A las cuales Abreu agrega en 1579 diez ordenanzas específicas para Córdoba. En Luque Colombres, 1974, pp. 298-301.

5. Doucet remarca que la importancia de las Ordenanzas en tanto "tasa y moderación" del "aprovechamiento y servicio personal" es que -más que innovando en la forma de explotación de los encomendados- estarían dando cuenta de la existencia de un orden previo, de normas o pautas de funcionamiento que fueron recuperadas por Abreu (Doucet, 1990, pp. 151-162). 
6. Para un análisis más detallado sobre "el tiempo de la algarroba" y el subsidio de la recolección a la economía colonial, así como sus aspectos culturales y de religiosidad, ver Quiroga (1999), Noli (1999) y Castro Olañeta (2006).

7. Uno de los informes más conocidos es el que en 1586 hizo el tesorero de la Real Hacienda Gerónimo Bustamante, quien expresaba que "aun una tasa que hizo Gonçalo de Abrego en que mando se les diese a los yndios el biernes y sábado para que trabajasen en sus chacaras e ylasen para su vestir, no se les guarda" (en Levillier, 1920, p. 221). A este se suman los informes de los religiosos que han sido analizados por Crouzeilles (2007).

8. Remitimos a la reciente investigación acerca de la gestión y proyecto político del gobernador Alonso de Ribera en el Tucumán de Carmignani (2013).

9. Ribera, esperanzado, le señala al Rey que gracias a la visita de sus tenientes, los naturales "en efecto saven que ellos an de acudir a acer lo que deven y que quien los maltratare seran castigados como se va hacienco y asi acuden con gusto y dilijencia a lo que se les manda y muchos yndios que andavan ausentes y huyendo de sus naturales y pueblos an tendio esta nueva y vienen a ressidir y vivir en ellos y cada dia bendran mas y estaran todos mas descansados y mantenidos que asta aqui y gran aumento y cessara la disminuycion que en los tienpos passados y conozida perdida en los venideros" (AGI. Charcas, 26, R. 8, N. 39). No nos detendremos en los Informes de los Tenientes de Naturales, remitimos al detallado estudio y a la transcripción de Carmignani (2013).

10. PARES - <http://pares.mcu.es/>

11. Podemos suponer que también se realizó una Numeración en el partido de Quilino, dependiente de la ciudad de Córdoba; sin embargo este aún no ha sido encontrado. Tal suposición se basa en que el Teniente Juan de Betanzos a cargo de dicho partido informa: "generalmente los encomenderos y pobleros se servian de todos los yndios e yndias sin reservar viejos de demasiada hedad ni niños que no llegavan a seis años y como se avian reservado en la numerazion algunos yndios y yndias por su demasiada hedad lo avian tenido por grande veneficio" (Carmignani, 2013, p. 155 , el resaltado me pertenece).

12. Nos referimos a las copias manuscritas que de la Numeración se encuentran en la Colección Gaspar García Viñas de la Biblioteca Nacional (Buenos Aires) bajo el número 4313 y en el Fondo Documental Monseñor Pablo Cabrera de la Biblioteca de la Facultad de Filosofía y Humanidades de la Universidad Nacional de Córdoba bajo el número 12765. Hemos contrastado el original con ambas copias verificando que se trata exactamente del mismo documento y que ambas transcripciones se realizaron del mismo original.

13. Tal como señala una misiva de Alonso de Ribera del 19 de marzo de 1607: "La ciudad de Santiago del Estero que es la caveza desta provincia lo mas principal y mas bien poblado della donde esta todo de paz y mejor sirven los indios tiene 42 vecinos con 4729 indios de doctrina" (AGI. Charcas, 26, R. 8, N. 39, el resaltado me pertenece). Aclaramos que se debe entender indios de doctrina como aquellos por los cuales se pagaba el estipendio a los curas doctrineros.

14. Sobre los Memoriales realizados en la Gobernación bajo el gobierno de Alonso de Ribera de los cuales se conservan tres, ver Doucet (1998), y Carmignani (2013). El Memorial de la ciudad de Santiago del Estero ha sido transcripto y publicado por Pérez Saez y Osán (1997).

15. La jurisdicción colonial de la ciudad de Santiago del Estero y el espacio prehispánico que habitaban las sociedades indígenas que fueron encomendadas a los vecinos de Santiago, ha recibido un renovado interés por parte de los investigadores (Castro Olañeta y Carmignani, 2009; Castro Olañeta, 2010a) y particularmente destacan los recientes estudios de integración interdisciplinaria de Farberman y Taboada (2012); y desde la arqueología de Taboada y Angiorama (2008 y 2010) y Taboada (2011).

16. Remitimos a los recientes trabajos de Taboada (2011), y Farberman y Taboada (2012), los cuales reflexionan sobre el cultivo de algodón y la producción de textiles en Santiago del Estero, preguntándose acerca de su origen prehispánico o colonial. 


\section{RÉSUMÉS}

Se presenta en este trabajo un documento inédito de 1607, el cual se ve precedido por una introducción referida al sistema de servicios personales en la gobernación del Tucumán y una contextualización dada por las Ordenanzas del gobernador Gonzalo de Abreu de 1576 y la gestión del gobernador Alonso de Ribera (1605-1611). El documento en cuestión se trata de una Numeración de los indios de las encomiendas del partido del Río Salado, en la jurisdicción de la ciudad de Santiago del Estero, cabecera de la Gobernación del Tucumán realizada en 1607. La numeración, que indica titular de cada encomienda y cantidad de indios tributarios, indias, reservados y caciques, fue realizada por uno de los Tenientes de Naturales nombrados por el gobernador Alonso de Ribera para visitar el territorio indígena y aplicar las Ordenanzas de 1576 que regulaban el servicio personal, con el objetivo de desagraviar a los indios de encomienda de los abusos de los encomenderos y sus pobleros. Finalmente, la información de este documento se contrasta con otras fuentes que permiten complementar la reconstrucción del mapa de encomiendas del partido.

We present in this paper an unpublished document of 1607 , which is preceded by an introduction referred to the system of personal services in the Governorate of Tucumán and contextualization that analyzes the ordinances given by Governor Gonzalo de Abreu in 1576 and the government of Alonso de Ribera (1605-1611). The document in question is an Indian Numbering of the partido of Río Salado, in the jurisdiction of the city of Santiago del Estero, head of the Governorate of Tucumán. The Numbering, indicating the name of the encomendero and quantity of tributary Indians, women, reserved and chiefs, was made by one of the Tenientes de Naturales designated by Governor Alonso de Ribera to visit the indigenous territory and implement the Ordinances of 1576 , to verify personal service, to make amends to the encomienda's Indians of the abuses of the encomenderos and their pobleros. Finally, the information in this document is contrasted to other sources that enable enriching our picture of encomiendas of partido del Río Salado.

\section{INDEX}

Keywords : Encomiendas, Personal Service, Indian Numbering, Río Salado, Santiago del Estero Palabras claves : Encomiendas, Servicio Personal, Numeración de indios, Río Salado, Santiago del Estero

\section{AUTEUR}

\section{ISABEL CASTRO OLAÑETA}

Facultad de Filosofía y Humanidades, Universidad Nacional de Córdoba, Argentina. Correo electrónico: isabelcastrox@gmail.com 